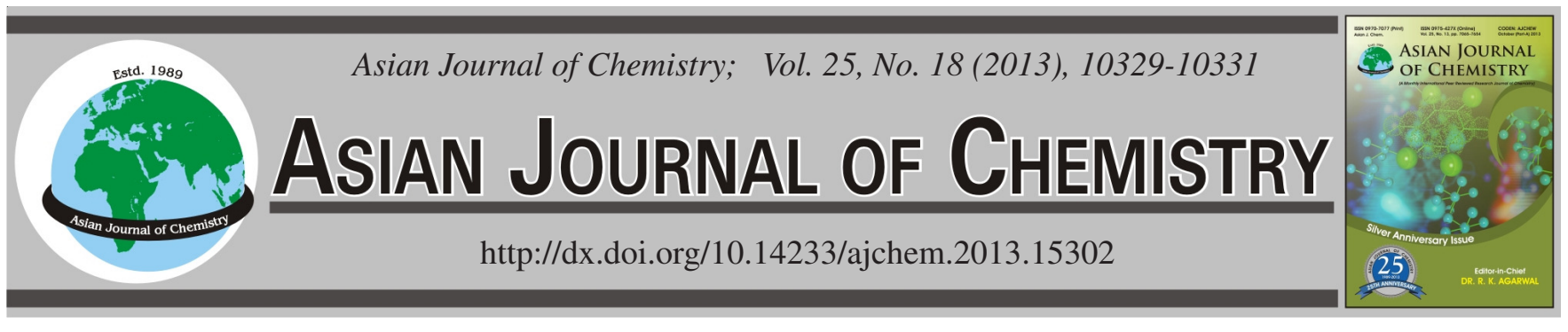

\title{
Decorative Coatings of Crystallite Type on Metallic and Non-metallic Surfaces
}

\author{
M.S. Satayev ${ }^{1}$, Sh. T. KoshKarbayeva ${ }^{1}$, A.S. TuKibayeva ${ }^{2, *}$ and E. Zh. Tuleshova ${ }^{3}$
}

${ }^{1}$ Department of Chemical Technology of Inorganic Substances, M. Auezov South Kazakhstan State University, South-Kazakhstan Region, Republic of Kazakhstan

${ }^{2}$ Department of Nanotechnology, M. Auezov South Kazakhstan State University, South-Kazakhstan region, Republic of Kazakhstan ${ }^{3}$ Department of Chemistry and Ecology, Kh.A. Yassawi International Kazakh-Turkish University, South-Kazakhstan region, Republic of Kazakhstan

*Corresponding author: Tel: +7 701 6587173; E-mail: tukibayeva@inbox.ru

(Received: 11 February 2013;

Accepted: 14 November 2013)

AJC-14395 The results of decorative coatings of 'crystallite' type on metallic and non-metallic surfaces are presented in this work. We propose the
low-temperature chemical method that allows receiving the "crystallite" pattern with a preliminary assessment of decorative coating
quality on all, including non-metallic materials. For this, at first a product is dipped for a few seconds into the saturated solution of copper
salt at the temperature of $80-90^{\circ} \mathrm{C}$ for metals and $60^{\circ} \mathrm{C}$ for polymeric materials. At drying the product on air "crystallite" type patterns are
formed onto its surface. If poor quality pattern is received, then it is easily washed off with water, thereupon repeating previous operations
the qualitative patterns can be obtained. To fix the received in such way patterns of the product they are treated by gas, containing
phosphine.

Key Words: Decorative coating, Gas, Containing phosphine, Copper phosphide, Galvanic sedimentation, Toning.

L

\section{INTRODUCTION}

In present times, the new technologies of metal coatings by supersonic hit of the particles on surface have widespread applications $^{1-3}$. Particle acceleration to supersonic speeds is carried out by compressed air. At this, the metallization of powder materials (aluminum, copper, zinc, nickel, tin, lead, babbit) is provided by gas-dynamic method.

The advantages of this technology: is used only compressed air and electro energy. There is no heating and oxidation of the metal particles, padding and deformation, changes of the structure and phase composition of metals; no harmful or aggressive gases, substances, radiation and other harmful factors; technological ease of coatings, cause widespread use of this method ${ }^{3}$.

Scientists invented the method of metal coating, which involves evaporation on pre-heated substrate to a thickness of not less than $1 \mu \mathrm{m}$ of pure metal film with a high electrical and thermal conductivity, such as aluminum and copper, with an average grain size of at least $3 \mu \mathrm{m}$ in inert gas stream containing impurities less than $10 \%$, with the density, which provides the collision of substrate metal atoms with atoms of inert gas such as helium at a pressure of 2-10 $\mathrm{Pa}^{4}$.

The use of metallic coatings on glass in art and decorative purposes was studied. It was shown that firing of glass products at the temperature range from $540-630^{\circ} \mathrm{C}$ with the most intense effect on the colour characteristics of metallic coatings ${ }^{5}$. It is also known a method ${ }^{6}$, ion-plasma deposition of titanium or its compounds (oxide, nitride, carbide) as a result of electric arc evaporation in a vacuum, which can be used for decorative and artistic processing of glass, ceramics and metal. Feeding into the vacuum chamber gas reagents, get different colours deposited film ${ }^{7}$.

It were also researched phosphate-based glasses of the general formula $\mathrm{Na}_{2} \mathrm{O}-\mathrm{CaO}-\mathrm{P}_{2} \mathrm{O}_{5}$ are degradable in an aqueous environment and therefore can act as antibacterial materials through the inclusion of ions such as copper ${ }^{8}$. In this study, $\mathrm{CuO}$ and $\mathrm{Cu}_{2} \mathrm{O}$ were added to $\mathrm{Na}_{2} \mathrm{O}-\mathrm{CaO}-\mathrm{P}_{2} \mathrm{O}_{5}$ glasses $(1-20$ mol \% $\mathrm{Cu}$ ) and $\mathrm{X}$-ray absorption spectroscopy and highenergy X-ray diffraction used to probe the local environment of the copper ions. Copper K-edge X-ray absorption near-edge structure spectra confirm the oxidation state of copper to be predominantly $2+$ in all samples regardless of which copper oxide was used in the preparation. The X-ray absorption nearedge structure results suggest the structural environment of copper to be octahedral with respect to oxygen in all samples. The high-energy X-ray diffraction results yield a $\mathrm{Cu}-\mathrm{O}$ nearestneighbour distance of $1.98 \AA$ and associated coordination number of approximately six, both consistent with octahedral 
coordination. Analysis of the extended X-ray absorption fine structure data also yields structural parameters consistent with copper in an octahedral environment. The high-energy X-ray diffraction and extended X-ray absorption fine structure results reveal a Cu-P distance of $3.13 \AA$, which confirms that the copper ions are coordinated within the phosphate glass network and not phase-separated in domains of copper oxide.

The coatings, obtained by chemical or electrochemical methods are widespread in large-scale production for protection of metals from corrosion, decoration of products, for giving special properties of products surface ${ }^{6}$. Galvanic metal coatings of plastics and other insulators are widely used for protective and decorative fixing of various products as for industrial use in manufacturing various machines so devices (especially radio and electronic). Field and scale of application of these coatings with the further progress of the technology are continuously increasing, because metallization allows obtaining materials with high valuable combination of physical and mechanical, chemical and performance properties of metals and dielectrics as reported by Melashchenko 9 .

A variety of modern chemical methods of metallization requires a focused review and systematization of information, collected at the present time, for optimization and further efficient use, so the aim of this work was the review of the chemical methods of metallization.

Decoration of metallic and non-metallic surfaces is widely used in manufacturing instruments, equipments and products for household purposes. For this purpose in industry "Crystallite" type coatings are used. This process is realized as: a layer of tin with thickness of 3-4 $\mu$ m made by standard sulphate electrolyte is electrochemically coated onto the prepared surface of metal items. After tin-coating the items are heat-treated (to surface melting) on the electric furnace at $300-350{ }^{\circ} \mathrm{C}$. The pattern formed in the film is not seen. It is revealed only after secondary tin-coating in sulphate electrolyte, containing no more than $1 \mathrm{~g} / \mathrm{L}$ of glue and $3 \mathrm{~g} / \mathrm{L}$ of phenol at the current density of 0.1-0.2 A/dm during 15-20 $\mathrm{min}^{6}$. Disadvantages of this method are the using of high temperatures to form a crystalline pattern, which makes it unsuitable for non-metallic materials, in addition the pattern is revealed only after secondary tin-coating, which complicates a preliminary assessment of the crystallite pattern.

\section{EXPERIMENTAL}

There are several ways of phosphine production. This is a hydrolysis of elementary phosphorus, alkaline decomposition of phosphoric, thermal decomposition of lower phosphorus acids, interaction of phosphonium halogenides with water or alkali and treatment of some phosphides with water or water solutions of acids ${ }^{10}$. Under laboratory conditions, it is convenient to obtain phosphine by decomposition of zinc phosphide with sulfuric acid or hydrochloric acid. Zinc phosphide is not deficient, as it is the major component of the means to deal with rodents and produced in industrial scales. In our experiments for production of phosphine by decomposition of zinc phosphide with solutions of 10-15\% sulfuric acid. At this produced gas, containing phosphine contained a small amount of hydrogen.
Surface treatment of the sample of gas, containing phosphine was carried out in a special airtight chamber. For this, the sample was placed into the chamber, then nitrogen was passed through it to displace the air, in order to prevent interaction between phosphine and oxygen. After that, gas, containing phosphine was let into the chamber until stopping of its absorption on the sample surface. Under the influence of phosphine the copper sulphate surface crystals were converted into copper phosphide $\mathrm{Cu}_{3} \mathrm{P}$. The sample coated by copper phosphide was washed with running water and dried in the air. Received semi-bright film has a colour from darkgray to black. The film has pronounced metallic properties, possesses a metallic luster and is a good electricity conductor.

\section{RESULTS AND DISCUSSION}

The film thickness was $0.3-0.6 \mu \mathrm{m}$, depending on the concentration of copper sulphate, material base and its surface condition. Specific discharge of copper sulphate per $1 \mathrm{~m}^{2}$ of copper-phosphorus film with thickness of $0.5 \mu \mathrm{m}$ was 15-16 $\mathrm{g}$, phosphine of $1.0-1.2 \mathrm{dm}^{3}$.

The dark colour dominates in the obtained coating, in which individual sectors differ only in contrast (Fig. la), that's why for obtaining patterned coatings that differ not only in contrast and color, we carried out several additional operations: etching and thin films sedimentation of non-ferrous metals, toning, etc.

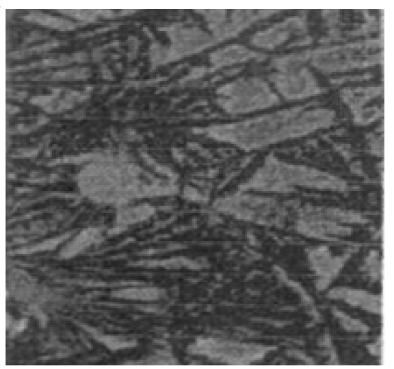

a

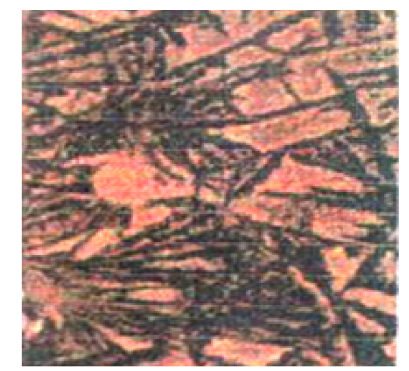

b
Fig. 1. Decorative coatings, received on the basis of surface crystals of copper sulphate converted into copper phosphide (D: 1:1). a untreated, $\mathrm{b}$ - after treatment by etching

Thus, we received decorative coatings, which were black crystals on a pink background at the etching in the solution of $\mathrm{CuCl}_{2}-100 \mathrm{~g} / \mathrm{L}, \mathrm{HCl}-190 \mathrm{~g} / \mathrm{L}$ at $40{ }^{\circ} \mathrm{C}$ for $2.5 \mathrm{~min}$ (Fig. lb).

By galvanic sedimentation of tin layer from electrolyte of the following composition, g/L: $\mathrm{SnSO}_{4}-40, \mathrm{H}_{2} \mathrm{SO}_{4}-160$, at the room temperature and current density of $2,5 \mathrm{~A} / \mathrm{dm}^{2}$ within 5 min coatings were produced. They were black crystals on a light background (Fig. 2a).

For toning the electrolyte of the following composition was used, g/L: $\mathrm{CuSO}_{4} \cdot 5 \mathrm{H}_{2} \mathrm{O}-37, \mathrm{KNaC}_{4} \mathrm{H}_{4} \mathrm{O}_{6} \cdot 4 \mathrm{H}_{2} \mathrm{O}-35$, $\mathrm{NaOH}-25$.

Freshly prepared electrolyte initially was treated under current for $48 \mathrm{~h}$. The process was carried out at the room temperature and current density of $0.015 \mathrm{~A} / \mathrm{dm}^{2}$ within $2-15$ min. Depending on the time of toning multi-coloured coatings with crystalline patterns whose colour changed from yellow to red, purple, green and blue were received. Some of the tinted coatings are shown in the Fig. 2b-d. 


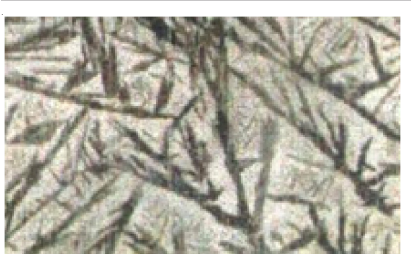

a

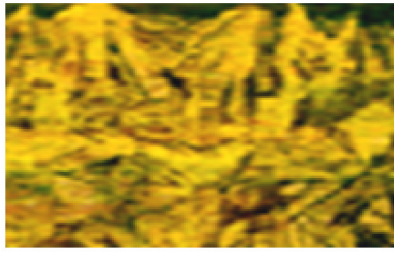

C

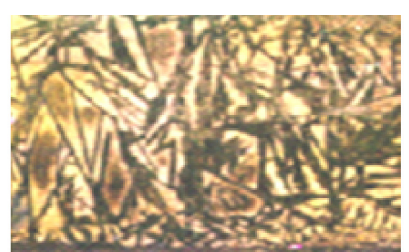

b

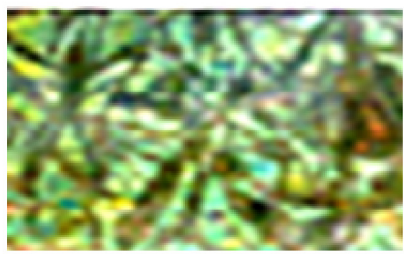

d
Fig. 2. Decorative coatings on the basis of copper phosphide after giving additional effects by metal sedimentation (a) and toning (b, c, d)

For obtaining the patterned coatings on the surface of polymer materials the preliminary preparation was carried out, the main purpose was to provide surface watering by copper sulphate solution. With this purpose, the sample surfaces were etched by solutions of various acids according to Shalkauskas and Vashkyalis ${ }^{11}$. On prepared surfaces, as well as on metal samples, at $60{ }^{\circ} \mathrm{C}$ the copper salt solution, crystalline patterns were obtained, which then were converted to copper phosphide. To increase decorative effect, the obtained picture is subjected to chemical colouration in the solution of $\mathrm{g} / \mathrm{L}: \mathrm{H}_{2} \mathrm{C}_{2} \mathrm{O}_{4} \cdot \mathrm{H}_{2} \mathrm{O}$ $100, \mathrm{CuSO}_{4} \cdot 5 \mathrm{H}_{2} \mathrm{O}-175, \mathrm{NaOH}-88$, at the temperature of 20 to $30^{\circ} \mathrm{C}$.
Coloration was carried out in an aluminum container in direct contact of the item with aluminum for $0.5 \mathrm{~h}$ at continuous shaking of the item. Meanwhile, the appearance of coating represented large patterns of copper phosphide in black colour on a dark-blue background ${ }^{12}$.

\section{REFERENCES}

1. V.F. Kosarev, S.V. Klinkov and V.N. Zaikovsky, Russia Patent 2468123 (2010).

2. V.A. Klimenov, V.M. Buznik and K.V. Brozna, Russia Patent 2465968 (2011).

3. Sh. T. Koshkarbayeva, Ph.D. Dissertation, Development Process Based on a Synthesis of the Copper-Phosphorus Films, M. Auezov South Kazakhstan State University, p. 111 (2002).

4. L.M. Larin and V.I. Rakhovsky, Russia Patent 2067130 (1996).

5. S.V. Nikolenko, Design. Mater. Technol., 2, 81 (2010).

6. M.A. Schluger, Galvanic Coatings in Machine, Mechanical Engineering, p. 240 (1985).

7. D. Parfenov, Russia Invention, 2154124 (2000).

8. D.M. Pickup, I. Ahmed, V. FitzGerald, R.M. Moss, K.M. Wetherall, J.C. Knowles, M.E. Smith and R.J. Newport, J. Non-Crystalline Solids, 352, 3080 (2006).

9. N.F. Melashchenko, Galvanic Coatings of Dielectrics, Minsk, Belarus, p. 176 (1987).

10. J. Van-Weser, Phosphorus and its compounds, Moscow, Chemistry, p. 687 (1962).

11. M. Shalkauskas and A. Vashkyalis, Chemical Metallization of Plastic, Leningrad, Chemistry, p. 144 (1985).

12. M.S. Satayev, L.M. Daurenbekova and Sh.T. Koshkarbayeva, Kazakhstan Patent 12954 (1994). 